\title{
Fire risk analysis with a performance-based fire safety engineering approach and FDS models for underground facilities in Gran Sasso National Laboratories
}

\author{
M. Tobia ${ }^{1}$, R. Tartaglia ${ }^{1}$, A. Giampaoli ${ }^{1}$, R. Perruzza $^{1}$ \& G. Farina ${ }^{2}$ \\ ${ }^{I}$ PPS Department, National Institute of Nuclear Physics, \\ Gran Sasso National Laboratory, Italy \\ ${ }^{2}$ Department of Industrial and Information Engineering \& Economics, \\ University of L'Aquila, Italy
}

\begin{abstract}
The aim of this work is the application of a performance-based approach in the field of the Fire Safety Engineering within the Gran Sasso National Laboratories (LNGS), one of the structures owned and managed by the National Institute for Nuclear Physics (INFN). CFD (Computational Fluid Dynamics) models provide a solid foundation on which a complete assessment of the different choices and procedures of evacuation management might be performed. These choices take into account, not only the characteristics of the surrounding environment and the accident scenario, but also the psychological and human aspects induced in people involved in an emergency event. The analysis has been implemented through the development of fire simulation models FDS (Fire Dynamic Simulator of the NIST) applied to new experimental installations, facilities and utilities in one of the LNGS underground areas. The object of the study has been the definition and simulation of a fire caused by an electrical cabinet devoted to the new experimental apparatus named "LUNA-MV" located inside the interferometer tunnel of the LNGS. The analysis addressed the choices in the preliminary design of the safety systems and in the optimization of the technical, economic and design parameters taken into account for each hypothesized event scenario. The work allowed also identifying the crucial factors for reviewing and optimizing the LNGS Emergency Plan, thus providing useful elements to support the LNGS users' training.

Keywords: safety, fire safety engineering, CFD, FDS, confined space, underground laboratory.
\end{abstract}




\section{Gran Sasso National Laboratories - INFN}

The Gran Sasso National Laboratories (LNGS) are one of the experimental research centres belonging to the Italian National Institute of Nuclear Physics (INFN). The LNGS facility is made up of two main areas:

- External Operations Centre in Assergi, L'Aquila;

- Underground Laboratories.

Both of the areas are located in the heart of Gran Sasso and Monti della Laga National Park. The underground laboratories, housing about 20 experiments, are located under a rock layer of about 1,400 m thickness, acting as a shield against cosmic radiation; the underground cavity is just in the middle of a huge reservoir, along the Gran Sasso highway tunnels (a double-tunnel 10,500 m long gallery). The research areas in which the laboratories operate or plan to operate are:

- the study of rare nuclear phenomena;

- the study of more penetrating components of cosmic rays;

- neutrino physics;

- dark matter.

LNGS consists of three experimental halls of about $100 \times 20 \times 20 \mathrm{~m}^{3}$ each: Hall A, Hall B, Hall C. The connection among the halls is achieved by other smaller galleries: Car tunnel, Truck tunnel, connecting tunnels.
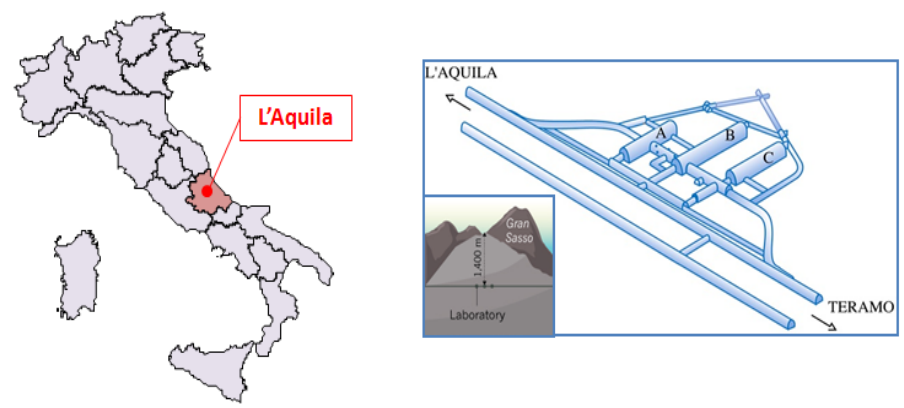

Figure 1: Gran Sasso National Laboratories: Underground Laboratories.

From the "safety point of view", besides health and safety regulations in the work place, according to the European Directive Seveso III (2003/105/CE), LNGS are classified as major accident hazard plant because of Experiments using and storing about big amount of substances classified dangerous to the environment [1]. In compliance with Seveso, LNGS have adopted a Safety Management System implemented through 16 Procedures and Operating Instructions. Moreover, before starting any activity or new project/experiment, LNGS and Experimental Collaboration must realize a Safety Risk Analysis in order to evaluate the likelihood of occurrence of possible events and to guarantee the highest safety standards in a complex system such as the one in which LNGS are involved. 


\section{LUNA-MV experiment}

LUNA-MV (Laboratory for Underground Nuclear Astrophysics) is an experimental project for the research in the field of Nuclear Astrophysics, studying in particular the reaction inside stars. Those reactions are essential for the energy production and the composition of chemical elements.

LUNA-MV foresees the installation of an accelerator of 3.5 MV inside the underground laboratories, in the Node B of the interferometer gallery (Fig. 2).

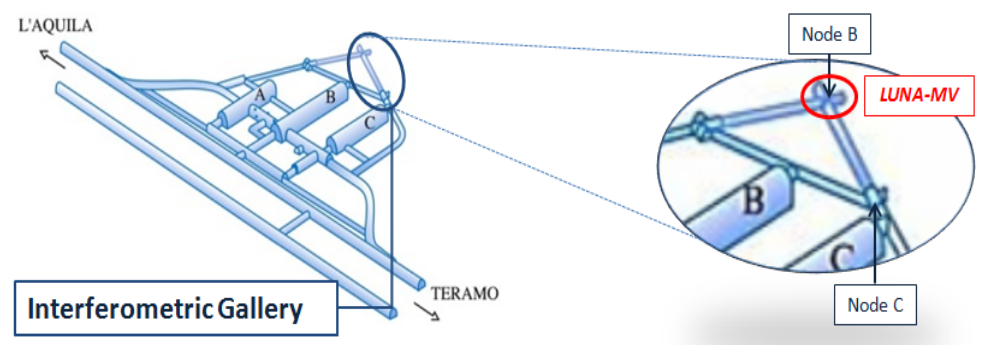

Figure 2: $\quad$ The interferometer tunnel and the Node B.

The interferometer tunnel is in the northern part of LNGS. It consists of a system of tunnels forming a triangle whose catheti are about $90 \mathrm{~m}$ long, $5 \mathrm{~m}$ wide and $5 \mathrm{~m}$ high. In order to ensure the isolation of the experimental site from the surrounding environment, the accelerator will be installed in the isolated area of the junction-point (node) B, an underground "spot" of about $200 \mathrm{~m}^{2}$. The isolation will be guaranteed by the installation of reinforced concrete shielding doors about $1 \mathrm{~m}$ thick. Furthermore, the defined location is made more critical because of the presence of dripping water coming from the walls and captured by the drainage systems: a complete network of pipes running below LNGS road level.

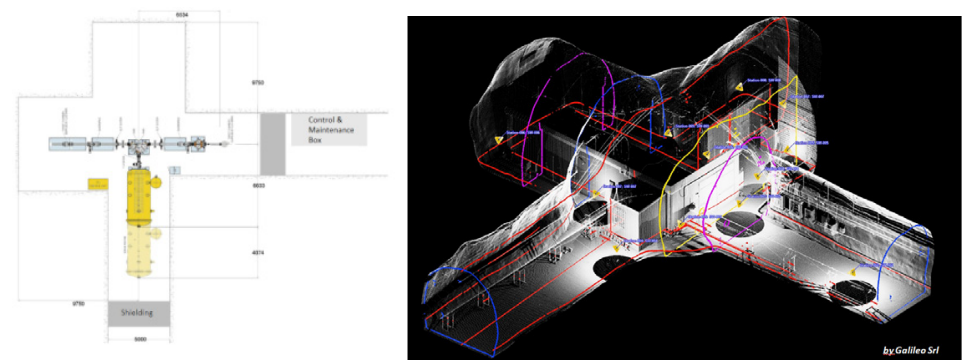

Figure 3: A plan of LUNA-MV experiment in the Node B (left); Laser scan of the installation site: interferometer galleries and Node B (right). 


\section{LUNA-MV fire scenario: FSE performance-based approach}

Fire Safety Engineering (FSE) can be defined as an engineering-performance approach (Fire Engineering), followed above all in Anglo-Saxon countries, based on prediction of the dynamic evolution of the fire through the application of suitable calculation models physically based (physically sound).

The strength of this methodological approach is its extreme flexibility, which allows the simulation of fires with very high level of complexity, after a careful evaluation of a number of input data (geometry of the calculation domain, ventilation conditions, type and amount of fuel, and so forth) to be assigned in detail dependant of the model accuracy.

FSE can be then summarized as the application of engineering principles, good construction rules and good-sense judgments based on the scientific assessment of the phenomenon of combustion, of the effects of fire and human behaviour in emergency condition [2]. Based on these concepts, the fire risk analysis carried out for the LUNA-MV project aimed to identify both the best technical choices for the protection of human life and the best design for the protection of property and of the environment. Moreover, this methodology of the FSE is a modern tool for assessing the safety of a building or activity, giving out the result of: both quantifying the fire risk and its effects and determining the best preventive and protective measures needed to limit the consequences of the fire itself.

First of all, the analysis focused on the fire scenario definition and characterisation, taking into account:

- ignition source;

- materials involved;

- geometry of the site;

- boundary conditions (temperature, ventilation, humidity).

The fire scenario interested the interferometer tunnel of LNGS, and in particular the tunnel connecting the junction point (nodes) B C. The hypothesis was a fire ignited from an electrical cabinet installed close to the $1 \mathrm{~m}$ thick concrete shielding door of the experiment. A ventilation measurement campaign has been performed in order to identify a realistic speed profile of the ventilation. The measure interested two sections of the interferometer tunnel and 9 measurement points have been identified for each of the two sections.
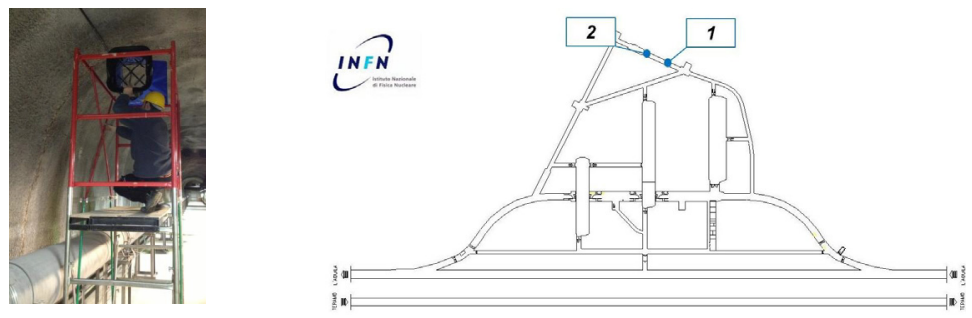

Figure 4: A ventilation measure in the interferometer gallery (left); the two measurement's sections (right). 
The results of the site definition are summarized in Table 1.

Table 1: Site definition and characterisation.

\begin{tabular}{|c|c|}
\hline Specifics & Description \\
\hline Ignition source & Electrical (fire from electrical cabinet) \\
\hline \multicolumn{2}{|l|}{ Materials involved } \\
\hline \begin{tabular}{|l|l|} 
Concrete \\
\end{tabular} & $\begin{array}{l}1 \mathrm{~m} \text { thick shielding door; on the walls of the } \\
\text { tunnel }\end{array}$ \\
\hline Steel & Shell of the electrical cabinet \\
\hline \begin{tabular}{l|l|} 
& Cables \\
\end{tabular} & $150 \mathrm{~kg}$ of cable inside the electrical cabinet \\
\hline \multicolumn{2}{|l|}{ Geometry of the site } \\
\hline \begin{tabular}{l|l} 
& Tunnel \\
\end{tabular} & $50.0 \times 4.5 \times 4.7 \mathrm{~m}^{3}$ \\
\hline \begin{tabular}{l|l} 
& Cabinet \\
\end{tabular} & $6.0 \times 2.0 \times 1.0 \mathrm{~m}^{3}$ \\
\hline \multicolumn{2}{|l|}{ Boundary conditions } \\
\hline \begin{tabular}{l|l} 
& Temperature \\
\end{tabular} & $12^{\circ} \mathrm{C}$ \\
\hline Humidity & $75 \%$ \\
\hline Ventilation & Parabolic speed profile \\
\hline
\end{tabular}

These elements represent the starting point on which Computational Fluid Dynamics (CFD) models lay their basis and, in particular, they are the input data used in the definition of the simulation and modelling of the fire scenario on Fire Dynamic Simulator (FDS) code [3, 4].

\section{Modelling of the fire scenario with FDS}

In order to obtain a reliable fluid dynamic model, the real scenario has been modelled by the use of FDS by NIST. For the display of the simulation results the post-processor Smokeview (SMV) has been used. Starting from the input element of Table 1, it was possible to model the geometry of the interferometer tunnel, the electrical cabinet and the concrete door, the ventilation and the boundary conditions in the site. Only a limited part of the interferometer gallery was modelled. The limitation of the domain was necessary to meet the computing power available but allowing to have a realistic and analyzable scenario.

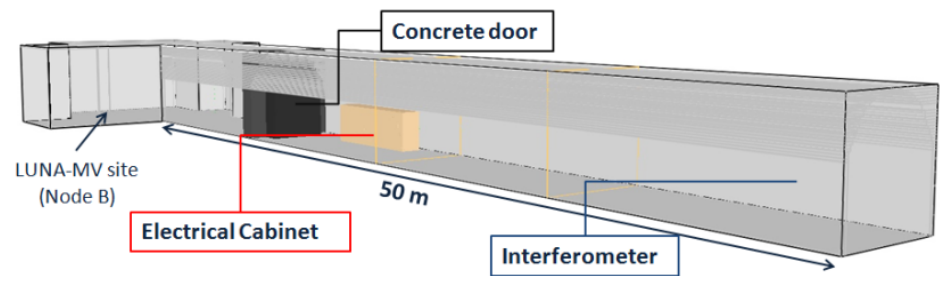

Figure 5: The FDS modelled scenario on SMV. 
The central point of the simulation was the definition of the Heat Release Rate (HRR) of the fire. On the basis of the tests on fires from electrical cabinet elaborated by the Institut de Radioprotection et de Suretè Nuclèaire (IRSN), it was possible to define the reference values of HRR [5].

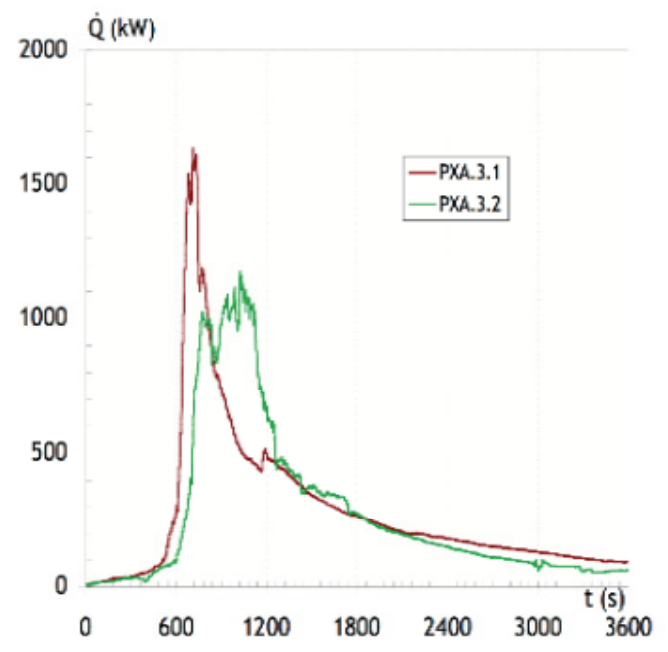

Figure 6: HRR curve for fires from electrical cabinet with open door (IRSN).

Starting from the experimental data, a calculation model was developed considering the following relations [2]:

$$
t_{f o}=\sqrt{\frac{H R R_{\max }}{\alpha}}
$$

Assuming an $\mathrm{HRR}_{\max }$ of $1,600 \mathrm{~kW}$ [4] and a rate of growth of the fire $\alpha$ of $0.00293 \mathrm{~kW} / \mathrm{s}^{2}$ (slow rate) eqn (1) gives the time to reach the flashover: $739 \mathrm{~s}$. The resulting flashover energy is calculated through the eqn (2) in $394 \mathrm{MJ}$.

$$
E_{\text {flashover }}=\frac{1}{3} \alpha t_{\text {fo }}^{3}
$$

The energy produced by the fire in the site is obtained with the calculation of the fire load in the compartment as a function of the material contained, their characteristics and the site area. The value of 4,850 MJ [6] obtained underlined that the flashover, with this energy, is reached after $171 \mathrm{~s}$ (calculated from eqn (2)). Knowing this value of $t_{\text {fo }}$, the $H_{R R}$ max for the case study was $86 \mathrm{~kW}$ (calculated from eqn (1)). 
Table 2: Scenario definition and simulation parameter on FDS.

\begin{tabular}{|l|c|}
\hline Ignition Source & $\begin{array}{c}\text { Electrical (Fire from electrical } \\
\text { cabinet) }\end{array}$ \\
\hline HRR & $86 \mathrm{~kW}$ \\
\hline Longitudinal extension of the domain & $50 \mathrm{~m}$ \\
\hline Height of the domain & $4.70 \mathrm{~m}$ \\
\hline Width of the domain & $4.50 \mathrm{~m}$ \\
\hline Mesh of the domain & $10 \mathrm{~cm}$ cubes \\
\hline Simulation time & $300 \mathrm{~s}$ \\
\hline Running time & $76 \mathrm{~h}$ \\
\hline
\end{tabular}

Table 3: Input parameter for the materials in the FDS simulation.

\begin{tabular}{|l|c|c|c|}
\hline Materials & $\begin{array}{c}\text { Conductivity } \\
(\mathrm{W} / \mathrm{mK})\end{array}$ & Density $\left(\mathrm{kg} / \mathrm{m}^{3}\right)$ & $\begin{array}{c}\text { Specific heat } \\
(\mathrm{kJ} / \mathrm{kgK})\end{array}$ \\
\hline Concrete & 1.6 & 2,400 & 0.75 \\
\hline Steel & 54 & 7,850 & 0.465 \\
\hline Cables & 0.235 & 0.24 & 1.39 \\
\hline
\end{tabular}

\section{Results of the simulation}

The first consideration in discussing the results of the simulation is that all the relevant factors are analysed starting from the concrete door close to the Node $\mathrm{C}$. LUNA-MV site (which is between the Node B and Node C, with Node B on the other side of the confinement door) is not directly interested by the effects of the combustion's products. The site, in fact, is interested above all in the phase of evacuation and emergency management. The principal parameters to be assessed as resulted in the simulation run can be summarized in:

- temperature inside the tunnel;

- smokes concentration in the tunnel;

- visibility condition;

- toxic gases concentration.

As regards the temperature, near the source of the fire and close to the concrete door of the experimental site there is a rapid increase of the temperature, as clearly shown in Fig. 7.

In Fig. 8, the dynamic evolution of the fire is pictured: after $60 \mathrm{~s}$, the values in the superior part of the tunnel are greater than $170^{\circ} \mathrm{C}$. In regime conditions, all along the domain, the temperatures resulted from the simulation reach values greater than $140^{\circ} \mathrm{C}$. 


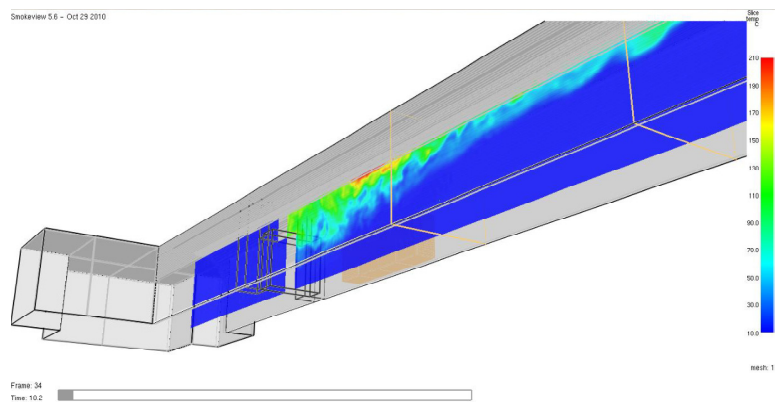

Figure 7: Temperature distribution in the tunnel after $10 \mathrm{~s}$, displayed by SMV.

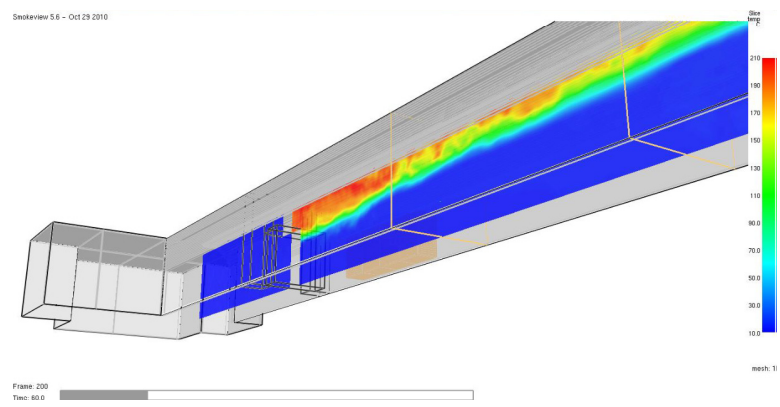

Figure 8: Temperature distribution in the tunnel after $60 \mathrm{~s}$, displayed by SMV.

Smokes' production is the most important and critical issue of fire in closed and confined spaces. For this reason, the analysis focused on two main aspects: toxic gases production and visibility conditions in the tunnel. Carbon monoxide was directly traced on FDS because of its high toxicity and production during a fire. After the starting peak, the production of $\mathrm{CO}$ reaches about $0,013 \mathrm{~kg} / \mathrm{s}$.

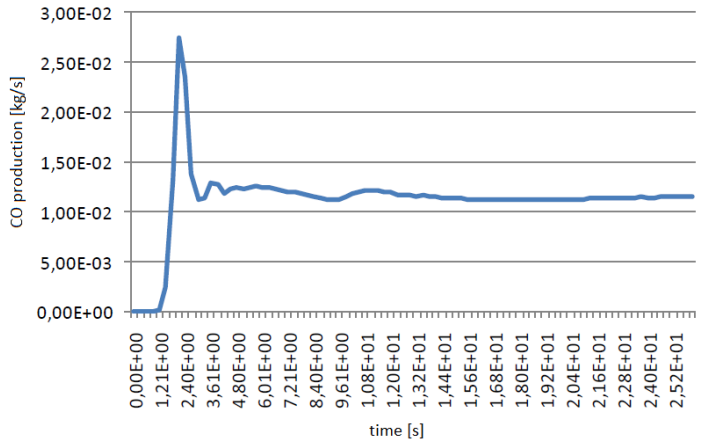

Figure 9: $\quad$ CO production in time. 
As regards the emergency management, visibility conditions in the tunnel are obviously a critical factor in terms of evacuation of the site, intervention of the rescue teams. The simulation represented in Fig. 10 showed an important decrease of the visibility: after $20 \mathrm{~s}$, the visibility is more than $20 \mathrm{~m}$ in the area of the Node $\mathrm{C}$, while near the cabinet and the door was significantly reduced to about $5 \mathrm{~m}$.

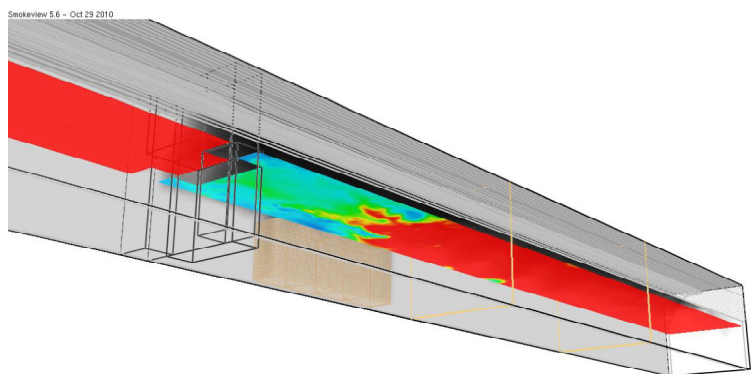

Frane

Figure 10: Visibility conditions in the tunnel after $20 \mathrm{~s}$, displayed by SMV.

\section{Technical and design solutions for the mitigation of risks}

On the basis of these results, the fire scenario represents critical element not only for the specific site but also for the entire underground structure. In order to avoid dangerous consequences for the experimental apparatuses located in the other underground areas and to guarantee the safety conditions for all the users, the assessment performed focused on the evaluation of measures for mitigation and containment of the event. At the end of the analysis, the working group detected two possible solutions:

- installation of a forced ventilation system;

- installation of a REI120 barrier.

\section{1 forced ventilation system}

The forced ventilation system has three main aims:

- facilitate the escaping of people;

- facilitate the intervention of the emergency teams [7];

- prevent, or delay, the phase of flashover.

The solution indentified is the installation of a fan on the top of the interferometer in the central point of the gallery. The suggested device is a $0.73 \mathrm{~m}$ diameter fan, with a flow rate of about $8,000 \mathrm{~m}^{3} / \mathrm{h}$ to ensure an optimal air flow in the interferometer gallery. The output of the simulation represented in Fig. 11 shows that thanks to the fan, the smokes are diluted and pushed towards the Node $\mathrm{C}$ reaching values of visibility higher than $15 \mathrm{~m}$. 


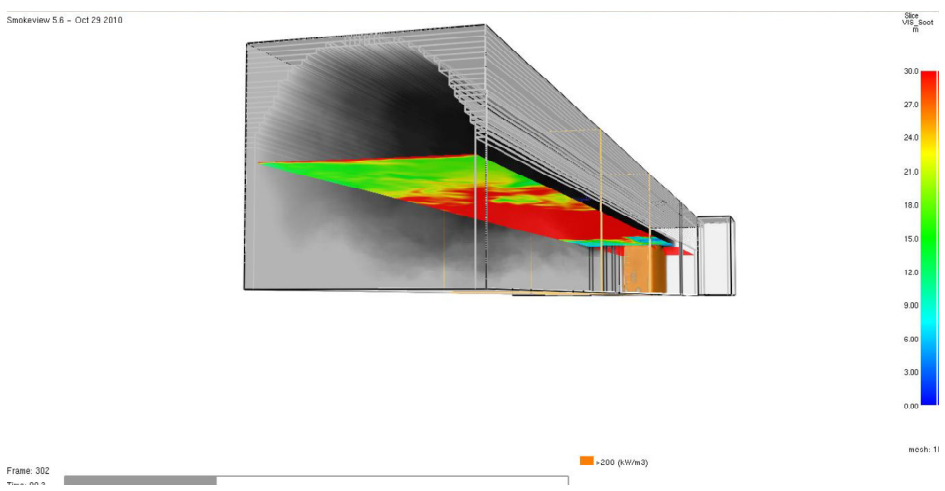

Figure 11: Visibility conditions in the tunnel after $20 \mathrm{~s}$ with forced ventilation, displayed by SMV.

\subsection{REI120 barrier}

The REI 120 barrier has the general aim to ensure isolation from flames, smokes and the combustion's products and to slow down the spreading of fire from a compartment to another for a limited period of time. The solution identified in the risk assessment analysis is the installation of the REI120 barrier at a distance of $13 \mathrm{~m}$ from the electrical cabinet.

The fire door of steel REI 120 is constituted by two hinged doors with panic handle push-type (opening in the direction of Node $\mathrm{C}$ ). The closing of the door creates a rapid reduction of visibility that makes difficult the evacuation and the intervention of rescue teams. In reason of this, backed up by the calculation model, it was decided to foresee a normally open door and to close it after 1 minute from the fire detection. The assumption made by the working group is that $60 \mathrm{~s}$ are a lapse of time long enough to allow the evacuation of occupants from experimental site of LUNA-MV and short enough not to facilitate too much the smoke propagation.

The output of the simulation shows that there is a decrease of the visibility after the closing of the door (visibility of about $3 \mathrm{~m}$ after $90 \mathrm{~s}$ ); however, the confinement of the area appears to be more efficient in terms of reduction of propagation of the smokes and of fire ignition in adjacent areas.

The results of the simulation with the fire-proof door installed are shown in Fig. 12.

\subsection{Comparative analysis of the proposed solutions}

For each of the solutions proposed, the working group have analysed advantages and disadvantages, as outlined in Table 4.

The comparison shows that the proposed solution "REI120 barrier" provides wider compared benefits in comparison with the "forced ventilation system" solution. 


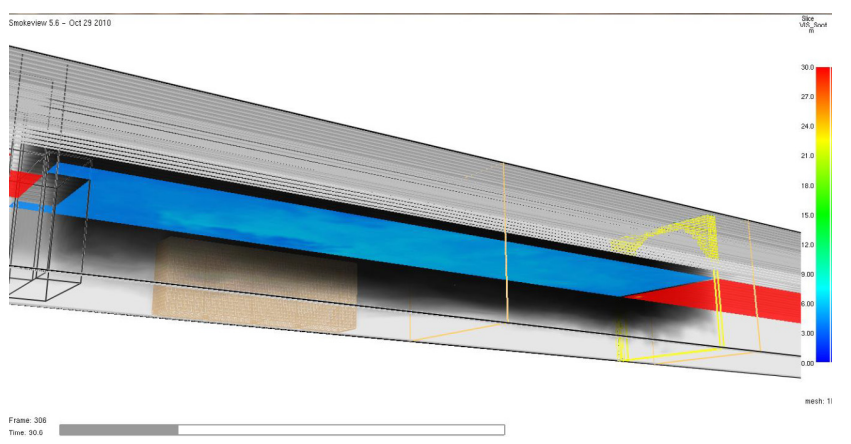

Figure 12: Visibility conditions in the tunnel after $90 \mathrm{~s}$ with REI120 barrier (yellow), displayed by SMV.

Table 4: Comparative analysis of the proposed solutions.

\begin{tabular}{|c|c|c|c|c|}
\hline Characteristics & \multicolumn{2}{|l|}{ REI120 barrier } & \multicolumn{2}{|c|}{ Forced ventilation system } \\
\hline Visibility & $\begin{array}{l}\text { Lower visibility and worse } \\
\text { evacuation's conditions }\end{array}$ & $X$ & $\begin{array}{c}\text { Smokes dilution and } \\
\text { better visibility: better } \\
\text { evacuation's conditions }\end{array}$ & \\
\hline Smokes spread & No propagation of smokes & & $\begin{array}{c}\text { Propagation of smokes } \\
\text { towards adjacent } \\
\text { environments }\end{array}$ & \\
\hline $\begin{array}{c}\text { Possible } \\
\text { domino effect }\end{array}$ & No propagation of the fire & & $\begin{array}{c}\text { High likelihood of } \\
\text { domino effect }\end{array}$ & \\
\hline $\begin{array}{c}\text { Fire } \\
\text { suppression }\end{array}$ & $\begin{array}{l}\text { Door closing helps to } \\
\text { extinguish the fire }\end{array}$ & & $\begin{array}{l}\text { Ventilation could } \\
\text { encourage the spreading } \\
\text { of the fire }\end{array}$ & \\
\hline $\begin{array}{l}\text { Evacuation and } \\
\text { intervention of } \\
\text { rescue teams }\end{array}$ & $\begin{array}{l}\text { Difficulty of movement } \\
\text { and breathing because of } \\
\text { the high temperatures and } \\
\text { smokes' concentration }\end{array}$ & & $\begin{array}{l}\text { Minor smokes' } \\
\text { concentration }\end{array}$ & \\
\hline Total cost & $\approx 11,000 €$ & n & $\approx 13,000 €$ & \\
\hline
\end{tabular}

\section{Conclusions}

LNGS' Prevention and Protection service is responsible for the management of complex activities in the lab; the LNGS activity "business core" is with no doubt the underground laboratory and the risks associated with the operativity. In this context, the present work faced a fire risk analysis on a performance-based approach according to Fire Safety Engineering.

The goal of the study was to evaluate the effects associated with the development of a fire and the response of the structure and materials: the analysis has been carried on through new methodologies and interactive tools, in 
a dynamic and innovative way, which overcome a purely empirical and prescriptive approach. This new approach allowed to identify the mitigation measures aimed at improving the evacuation's conditions and limit the fire's propagation to the adjacent areas. This represent a crucial aspect in the underground site with the activities and operations carried on in such a peculiar area.

The CFD, FDS models and risk assessment in environments with high technological complexity led to quantitative results and visual assessments of risk. In the interferometer tunnel the analysis resulted in the presence of critical conditions (temperature, visibility and smokes' production) in the first minutes (time period shorter than 5 minutes). The suggested solution of a REI120 barrier was a good compromise between confinement and evacuation needs, leading to limitation of smokes and fire's propagation in the other underground areas.

Moreover, taking into consideration the consequences, the immediately usable results and measurements allowed the revision and refinement of the current LNGS emergency plan. Human beings, usually considered as rigid elements responsive to the laws of fluid mechanics in the process of emergency evacuation, are in fact complex beings, responsive to neuro-dominant laws. Stress, panic, education, culture, experience are just some of the aspects occurring in an emergency evacuation. For this reason, the results of the present work represent the starting point for a more complete study of the evacuation's dynamics of people in confined areas, such as the Node B of LNGS.

\section{References}

[1] LNGS, Rapporto di sicurezza, 2011

[2] S. Marsella, L. Nassi, L'ingegneria della sicurezza antincendio e il processo prestazionale, EPC LIBRI, 2010

[3] NIST, Fire Dynamics Simulator (Version 5) - User's Guide, 2010

[4] NIST, Fire Dynamics Simulator (Version 5) - Technical Reference Guide, 2010

[5] M. Coutin, P. Guillou, Phenomenological description of actual electrical cabinet fires in a free atmosphere, IRSN, 2004

[6] A. Leonardi, G. Passaretti, Guida pratica alla valutazione del carico d'incendio, EPC LIBRI, 2010

[7] LNGS, Piano di Emergenza Interno rev. 03, 2009 